\title{
Learner Persistence in Adult Basic Education
}

Retaining learners is an ongoing challenge for adult basic education (ABE) programs, in which high attrition is common and accountability pressures are strong. Recently, researchers have called on the field to rethink the meaning of persistence from the learner's point of view, and studies have identified specific ways to support persistence. Their findings provide insights for structuring local practice in ways that may help more learners reach their goals.

Persistence is typically defined as the length of time adults attend a class or tutoring sessions, and therefore "dropping out" of a class is evidence of lack of persistence. Yet, as Comings, Parrella, and Soricone (1999) point out, some students "may withdraw when their goals for participation have been reached, which may not coincide with a program's definition of completion," and some may "leave one program and sooner or later enroll in another that better fits their needs." In addition, "Many adults who stop attending programs return when their circumstances change, often repeating this 'stopping out' cycle several times." From the student's point of view, persistence may continue through self-study or distance learning. Using attendance in class or in tutoring sessions as the only measure of persistence undervalues effective learning activities that should be encouraged (p. 4).

Comings et al. (ibid.) defined persistence as "adults staying in programs for as long as they can, engaging in self-directed study when they must drop out of their programs, and returning to programs as soon as the demands of their lives allow" (p. 3). Using this definition, they interviewed 150 adults in GED programs in 5 New England states about their past schooling, adult education experiences, and influences on persistence. Two aspects of educational experience were associated with persistence: (1) adults who had been involved in previous efforts at basic skills education, self-study, or vocational skills training were more likely to persist than those who had not; and (2) adults who had a specific goal (such as "help my children" or "get a better job") were more likely to persist than those who either mentioned no goal or said they were doing it for themselves. Among the positive forces mentioned by adults in this study were social support, goal setting, and progress toward reaching a goal.

The Longitudinal Study of Adult Learning sponsored by the National Center for the Study of Adult Learning and Literacy (Reder \& Strawn, 2001) is following a group of approximately 1,000 individuals in Portland, Oregon, without a high school diploma or GED, including equal numbers who had/had not recently enrolled in local adult education programs. Preliminary data show that the way in which participation is measured makes a difference. In contrast to focusing on time spent in one program, measuring hours accumulated in individual participation episodes reveals a broader pattern of participation that may include attendance at different programs with varying intensities and duration, as well as self-directed study.

By looking at this cumulative process of participation from the learner's perspective, practitioners may find better ways to support learners, for example, by enhancing their self-directed learning abilities and offering distance technology options for those unable or uninterested in attending classes (ibid). Programs adopting a learnercentered perspective can engage adults in understanding and managing the positive and negative forces that help and hinder learning and can design program structures that support persistence.

\section{- Forces Supporting or Hindering Persistence}

Adults start and stop attending educational programs for a variety of reasons. Quigley (1997) noted these factors:

- situational (problems with employment, finances, child care, family, transportation, health, abuse);

- institutional (program level or content, location, attendance/ reentry policies);

- dispositional (educational attitudes, self-efficacy, resilience, and attribution of failure);

- demographic (age, gender, cultural background); and

- emotional-relational (social support and encouragement, caregiving).

Persistence is highly individualized: for each learner, a "complex constellation" of factors (Long, 2001) contribute to enrolling, continuing in, and withdrawing from a program. For example,

- The persistence of 10 women learning English as a second language was most often tied to relationships in the program or their need for skills connected with caregiving (Cuban, 2003).

- In a study of 254 welfare recipients in $A B E$, dispositional variables better predicted persistence than did demographic and situational variables (Ziegler, Bain, Bell, \& Brian, 2003).

- Social support and child care factors were the only statistically significant forces in a survey of 119 GED students (King, 2002). 
Studies that account for the multiple roles that students play (e.g., Skilton-Sylvester, 2002) note different supports and hindrances. For example, an adult learner may be a parent, worker, and community member, and each role will have specific supports and hindrances.

\section{- Force-Field Analysis}

How can practitioners begin to make sense of the complex constellation of factors that contribute to persistence? NCSALL's Persistence Study (Comings et al., 1999) suggests using force-field analysis (based on the work of Kurt Lewin, 1951) which examines positive and negative forces that inhibit or support action in a particular direction. These forces exist on a continuum ranging from forces having no real effect to those having a very strong influence.

Parrella (2000) describes using force-field analysis as a brainstorming activity with students of English as a second language. Steps include identifying who or what makes it hard for them to persist; who or what helps them pursue their goals; whether there are more positive or negative forces; and which two forces do they most want to work on strengthening or lessening. Force-field analysis may be useful for helping individuals and groups of students formulate actions to increase persistence, and programs might use this information to devise operational strategies, such as extended hours or days of operation or additional locations; support services such as child care and transportation; and strategies that reduce psychological obstacles to persistence, such as negative early schooling experiences (Comings et al., 2003). However, it must be recognized that negative forces arising from the broader institutional, political, or cultural context may need to be dealt with at the program level or in collaboration with learners using participatory and critical approaches (Cuban, 2003).

\section{- Intake}

Negative forces often work quickly: a common finding of retention studies is that many adults who leave do so early. The first 3 weeks have been found to be particularly crucial (Quigley \& Uhland, 2000). Thus, retention really begins at intake, which sets the tone for the remainder of the experience. Most programs have intake procedures, but the information gathered is not always used to shape program policies, content, and delivery (Comings et al., 2003). In a study of intake procedures in 177 literacy, Even Start, ABE, and GED programs in Texas, Hubble (2000) found that programs may not use intake effectively to counter barriers to attendance and that some practices may actually contribute to institutional barriers. For example, one-third of programs do not ask about past schooling experiences; more than half ask about child care or transportation problems, but fewer than one-quarter provide such assistance; and learning styles are assessed but results are rarely used to determine placement or instructional delivery. Intake is often considered a onetime, static event rather than an ongoing, dynamic process that revisits learners' goals, barriers, and other issues that may change over time. Other research-based intake strategies include:
- Use of the Adult Education Persistence Scale, which measures schooling attitudes, self-efficacy, resilience, and attributions for success and failure, as an intake instrument (Ziegler et al., 2003);

- Use of a learning disabilities screening device, because some learners may be unaware of, or uncomfortable disclosing, disabilities (Goforth \& Jonik, 2001);

- A self-management/self-direction screening process (Goforth \& Jonik, 2001) to assess capacity for self direction and to identify ways to build these skills (Reder \& Strawn, 2001);

- Learner focus groups, which provide a forum for raising issues and concerns, give practitioners valuable feedback for assisting learners, and can evolve into learner support groups (Goforth \& Jonik, 2001);

- Moving pre-testing from the first week to a later class period (Rudy, 2003);

- Pre-enrollment opportunities for learners to observe classes and make peer contacts to ease the stress and anxiety in returning to school (Heffern, 2003); and

- In-depth interviews with new students that explore past schooling, reasons for dropping out of high school, and goals for education and the future, which can build into writing assignments and provide information for making referrals to social agencies that can assist with some barriers (Jones, 1998).

\section{- Social Support}

A key positive or negative influence on learner retention is social relationships. These include support or opposition from family, friends, and community; relationships among learners; and relationships between learners and teachers. Feeling respected by teachers and programs is an important persistence factor (Quigley \& Uhland, 2000; Ziegler \& Durant, 2001).

Women learning English as a second language persisted because of relationships and emotional reciprocity in the program and because of the ways in which learning supported their caregiving roles (Cuban, 2003). This suggests the importance of building a community that provides a "psychological and physical holding environment" to help learners' personal and social development. Persistence strategies need to address community, safety, and access issues. Communitybuilding activities include peer mentoring, problem-based learning, participatory programming, cooperative learning, peer support groups, phone calls to absent learners, flexible scheduling, a comfortable physical space, and child and elder care assistance. Safety is addressed by providing a non-threatening environment for personal disclosures and emotional development. Access is improved by flexible attendance rules to encourage return; off-site tutoring; friendly, meaningful intake; and humanistic formative assessment (ibid.).

Ziegler and Durant (2001) cited engagement as a significant influence on persistence. Several factors affected engagement: (1) beliefs about teaching and learning — teachers' belief in adults' ability to learn and adults' belief that participation in ABE has worthwhile outcomes; 
and (2) relationships-interactions between teachers and participants that show mutual respect and acceptance with opportunities for learners to form social and support relationships with each other.

A cohort is one type of social network that can provide necessary supports for persistence. Millar and So (1998) compared ABE students in a cohort group with students whose program was individualized. Students felt the cohort group offered support, a chance to exchange experiences and share difficulties, and a positive learning environment. It reduced their sense of isolation and helped them understand their past learning experiences. Millar and So's suggestions for using cohorts include:

- Encourage group work on setting learning goals and establishing learning schedules and learning habits;

- Encourage discussion on topics of interest to students such as reasons they dropped out of school, coping with being a student, and life changes they are experiencing; and

- Provide support for becoming a learner-a group can support the need to reorganize lives, reduce current commitments, and develop new styles of learning and time management skills.

\section{- Goal Setting}

Having a goal and making progress toward its achievement can be powerful motivators to persist in learning. A key finding of NCSALL's persistence study (Comings et al., 1999) was that adults who mentioned a specific goal were more likely to persist than those who had no goal. Persistence can falter with lack of progress, and sometimes goals must be revised and learners redirected toward new goals (Goforth \& Jonik, 2002b). Adult learners can be characterized by types of goals:

- Short-term students who participate intensely but briefly to accomplish a specific goal, such as admission to a training program or preparation for a citizenship test;

- Long-term students who attend for an extended period for the social interaction and sense of community;

- Mandatory participants who are required to attend as a condition of receiving some type of aid or to comply with conditions of parole.

What methods have proven effective to help learners with goal setting? Meader (2000) used a goal-setting questionnaire that included questions about positive and negative forces that might influence goal pursuit and action steps for goal achievement. During the fourth and the eighth weeks, learners revisited their goals to review the effects of positive and negative forces and reconsider the action steps. The teacher incorporated into instruction strategies to deal with the negative forces (such as math anxiety) that students had identified as potential hindrances. At the end of the course, men who persisted rated goals second and women third among factors that kept them coming to class.
Once goals and action steps have been established, teachers can use learner goals as the context for instruction. Programs should provide services that help students make progress as well as procedures that allow students to measure their own progress and increase self-efficacy about reaching their goals. Comings et al. (1999) suggest four elements of self-efficacy: Mastery experiences that allow an adult to be successful in learning, particularly early in the program and to cope with failure; Vicarious experiences provided by social models (e.g., successful former students who can serve as speakers during intake and orientation activities or as mentors and counselors; Social persuasion, or verbal assurances from teachers, staff, counselors, fellow students, family, and friends; and Learners physiological and emotional states. Life histories and dialogue journals can help identify the physical and mental health problems that can affect learning.

\section{Follow-up and Redirection}

Through ongoing, reflective dialogue, learners and teachers should regularly revisit goals to assess whether they are still relevant and achievable (Comings et al., 2003). Sometimes this results in redirection, which Goforth and Jonik (2002a) define as: (1) postponing the goal until serious situational barriers are under control; (2) shifting to a different goal path; (3) adjusting the goal up or down; or (4) taking a different route to the goal, which might mean switching to a program that better meets a learner's needs or withdrawing. However, "an informed decision to withdraw carries with it a plan for future action, and hope" (ibid., p. 33).

When learners stop attending, programs should attempt to maintain contact, keeping the door open for reentry. Although literacy programs may try to contact stopouts, they often lack a structure for maintaining continuity during absent periods (Hubble, 2000). Recognizing the need for accountability, Comings et al. (1999) suggest procedures for collecting evidence of "time-on-task" that can be credited to a program: time spent in classes; tutoring sessions; self-study through technology, media, or instructional materials; reading of new, more challenging materials; and engagement in community improvement efforts that require the use of literacy and math skills.

\section{- Conclusion}

Learner persistence is clearly a complex issue, and not all facets, such as curriculum, instruction, and assessment, can be addressed in this brief. The focus here is on the creation of an organizational culture that understands persistence from the learner's point of view and the development of an environment that both acknowledges and respects the learner's multiple contexts and roles and offers a safe space for identifying and pursuing educational goals. Some recommendations (Goforth \& Jonik, 2002b) include:

- Reviewing how goal achievement is defined by the program, developing a definition for retention based on a clear understanding of goal achievement, and using it to measure the effectiveness of retention strategies and approaches; 
- Determining reasonable expectations for satisfactory progress by learners that take into consideration the variations in learner goals;

- Reviewing program policies regarding attendance and withdrawal to ensure that they do not create additional barriers to persistence and reentry; and

- Involving learners in the development of the learning environment.

As Comings et al. (1994, p. 4) note, "A wider definition of persistence would allow practitioners to focus on helping adults become persistent learners who use episodes of program participation as critical parts of a comprehensive learning strategy that employs other forms of learning." Determining factors that influence an individual learner is often difficult because those who withdraw sometimes respond to practitioner or researcher inquiries about their departure with "socially acceptable responses," such as a lack of transportation or childcare (Quigley \& Uhland, 2000). For this reason, building trust and rapport and listening for the deeper meanings of what learners say are fundamental to finding ways to support persistence (ibid.).

\section{- References}

Comings, J. P., Parrella, A., \& Soricone, L. (1999). Persistence among adult basic education students in pre-GED classes. Cambridge, MA: National Center for the Study of Adult Learning and Literacy. Retrieved January 3, 2005 from http://gseweb.harvard.edu/ ncsall/research/report12.pdf (ERIC Document Reproduction Service No. ED 437 579)

Cuban, S. (2003). 'So lucky to be like that, somebody care': Two case studies of women learners and their persistence in a Hawai'i literacy program. Adult Basic Education, 13(1), 19-43.

Goforth, D., \& Jonik, M. (2001). What works: Recruitment and retention of Ontario Works clients-Phase 2. Ottawa: Workplace and Employment Preparation Branch, Ministry of Training, Colleges and Universities; National Literacy Secretariat, Human Resources Development Canada. Retrieved January 3, 2005 from http://www.collegeupgradingon.ca/projprtt/ whatwork/whatwork.pdf

Goforth, D., \& Jonik, M. (2002a). Retention through redirection protocol. Sudbury, Ontario: College Sector Committee for Adult Upgrading. Retrieved January 3, 2005 from http://www.collegeupgradingon.ca/projprrt/RthruR/ protocol/protocol.pdf

Goforth, D., \& Jonik, M. (2002b). Retention through redirection report. Sudbury, Ontario: College Sector Committee for Adult Upgrading. Retrieved January 3, 2005 from http://www.collegeupgradingon.ca/projrprt/ RthruR/report/report.pdf

Heffern, L. (2003). Improving student drop-out rates through student observations and peer contacts. McKeesport, PA: Pennsylvania Action Research Network. Retrieved January 3, 2005 from http://www.learningfrompractice.org/paarn/monos03/Heffern.pdf

Hubble, J. H. (2000). Intake procedures as a factor in identifying and addressing barriers to attendance of adult education students. M.A. Thesis, Southwest Texas State University. (ERIC Document Reproduction Service No. ED 443 982)

Jones, J. D. B. (1998, June). Retention and the GED. Focus on Basics, 2(B), 15-17. Cambridge, MA: National Center for the Study of Adult Learning and Literacy. (ERIC Document Reproduction Service No. ED 431 868)
King, C. (2002). Barriers affecting GED participation among recent high school dropouts. Adult Basic Education, 12(3), 145-156.

Lewin, K. (1951). Field theory in social science. NewYork: Harper \& Row.

Long, E. (2001). Enrolment and retention in adult basic education programs: Some theoretical implications of a National Study Follow-up Study. In R. O. Smith, J. M. Dirkx, P. L. Eddy, P. L. Farrell, \& M. Polzin (Eds.), AERC 2001. Proceedings of the 42nd Annual Adult Education Research Conference, June 1-3, 2001. East Lansing: Michigan State University. Retrieved January 3, 2005 from http://www.edst.educ.ubc.ca/aerc/2001/2001long.htm

Millar, R., \& So, J. (1998). Learning and talking together: Research investigating persistence and retention in adult Literacy programs. Winnipeg, Manitoba: Journeys Adult Education Program. Retrieved January 3, 2005 from http://www.nald.ca/fulltext/journeys/cohort.htm

Parrella, A. (2000). Focus on teaching supports and hindrances: A force-field analysis. Focus on Basics, 4(A), 19. Retrieved January 3, 2005 from http://ncsall.gse.harvard.edu/fob/2000/focteach.html (ERIC Document Reproduction Service No. ED 451 397)

Quigley, B. (1997). Rethinking literacy education: The critical need for practice-based change. San Francisco: Jossey-Bass

Quigley, B., \& Uhland, R. L. (2000). Retaining adult learners in the first three critical weeks: A quasi-experimental model for use in ABE programs. Adult Basic Education, 10(2), 55-68.

Reder, S., \& Strawn, C. (2001). Program participation and self-directed learning to improve basic skills. Focus on Basics, 4(D), 15-18. Retrieved January 3, 2005 from http://ncsall.gse.harvard.edu/fob/2001/reder2.html (ERIC Document Reproduction Service No. ED 451 397)

Rudy, E. (2003). Reducing the pattern of student drop-out after the first class session of ABE/GED classes through moving T.A.B.E. assessment from the first class session to the fourth class session. McKeesport, PA: Pennsylvania Action Research Network. Retrieved January 3, 2005 from http://www.learningfrompractice.org/paarn/monos03/Rudy.pdf

Skilton-Sylvester, E. (2002). Should I stay or should I go? Investigating Cambodian women's participation and investment in adult ESL programs. Adult Education Quarterly, 53(1), 9-26.

Ziegler, M., \& Durant, C. (2001). Engagement: A necessary ingredient for participation in adult basic education. In R. O. Smith, J. M. Dirkx, P. L. Eddy, P. L. Farrell, \& M. Polzin (Eds.), AERC 2001. Proceedings of the 42nd Annual Adult Education Research Conference, June 1-3, 2001. East Lansing: Michigan State University. Retrieved January 3, 2005 from http://www.edst.educ.ubc.ca/aerc/2001/2001ziegler.htm

Ziegler, M., Bain, S., Bell, S., \& Brian, D. (2003). Dispositional variables predicting the persistence of welfare recipients in adult basic education. In D. Flowers, M.-Y. Lee, A. Jalipa, E. Lopez, A. Schelstrate, \& V. Sheared (Eds.), AERC 2003. Proceedings of the 44th Annual Adult Education Research Conference, pp. 465-470. San Francisco: San Francisco State University.

Brief Author: $\quad$ Sandra Kerka, Ohio State University

Brief Editors: $\quad$ Erik Jacobson, CALPRO Mary Ann Corley, CALPRO 